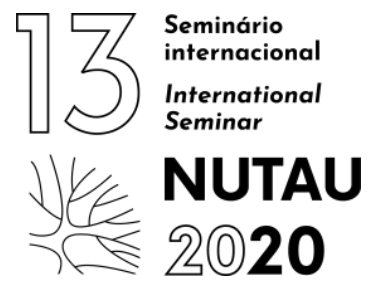

\title{
As áreas verdes no espaço urbano $O$ estudo de caso do bairro Cafezal em Londrina-PR, Brasil
}

Bruna Sthefany da Silva ${ }^{1}$, Joseane Pivetta ${ }^{2}$

${ }^{1}$ Centro Universitário Filadélfia - Unifil, discente do curso de arquitetura e urbanismo, bruna.sthefany@hotmail.com

${ }^{2}$ Centro Universitário Filadélfia - Unifil, docente doutora do curso de arquitetura e urbanismo, joseane.pivetta@gmail.com

RESUMO: Este artigo analisa a importância das áreas verdes e da infraestrutura verde nas cidades. O objetivo foi verificar a relação entre as questões legais e a realidade desses espaços do estudo de caso do bairro Cafezal em Londrina - Paraná, Brasil. Dessa forma, foi realizado o cálculo de índice de área verde (IAV), que é um dos instrumentos utilizados no planejamento urbano, a qual a unidade territorial apresentou um IAV de $34,80 \mathrm{~m}^{2} / \mathrm{hab}$, superior ao IAV mínimo de $15 \mathrm{~m}^{2} /$ hab., sugerido pela Sociedade Brasileira de Arborização Urbana (SBAU). Entretanto, ao investigar cada espaço que compõem as áreas verdes, como as áreas de preservação da mata nativa, as praças, os fundos de vales e as áreas ajardinadas do sistema viário, o resultado demonstra uma série de deficiências, principalmente em relação à falta de uma arborização adequada, que reflete desde o processo de implantação até o sistema de manejo, incluindo poda, remoção e destinação dos resíduos arbóreos.

PALAVRAS-CHAVE: Áreas verdes, infraestrutura verde, arborização, qualidade de vida

ABSTRACT: This article analyzes the importance of green areas and green infrastructure in cities. The objective was to verify the relationship between legal issues and the reality of these spaces of the case study of the Cafezal neighborhood in Londrina - Paraná, Brazil. Thus, the calculation of the green area index (IAV) was performed, which is one of the instruments used in urban planning, which the territorial unit had an IAV of $34.80 \mathrm{~m}^{2} /$ inhabit, higher than the minimum IAV of $15 \mathrm{~m}^{2} / \mathrm{hab}$., suggested by the Brazilian Society of Urban Arborization (SBAU). However, when investigating each space that makes up the green areas, such as the native forest preservation areas, the squares, the valley bottoms and the garden areas of the road system, the result shows a series of deficiencies, mainly in relation to the lack of adequate afforestation, which reflects from the implantation process to the management system, including pruning, removal and destination of tree residues.

KEYWORDS: Green areas, green infrastructure, afforestation, quality of life

\section{INTRODUÇÃO}

Com o intenso processo de urbanização e crescimento das cidades houve uma redução drástica da arborização e das áreas verdes no espaço urbano, que perderam lugares para o desenvolvimento da infraestrutura cinza, como construção de vias e viadutos, devido à utilização intensa dos automóveis, o que geram impactos ambientais negativos atribuídos a degradação da natureza e dos recursos hídricos. Nesse contexto, tem-se discutido a respeito da importância da conservação do meio ambiente no planejamento e desenvolvimento das cidades através do sistema de infraestrutura verde. $O$ conceito de infraestrutura verde visa a implantação de planos sustentáveis, de forma a conservar a estrutura e os processos das paisagens no uso e ocupação do solo urbano, integrando objetivos ambientais e econômicos, para o desenvolvimento das cidades, que contribuam para a saúde e a qualidade de vida da população (Vasconcellos, 2015). A arborização urbana é um dos quesitos importantes da infraestrutura verde, pois proporciona diversos benefícios às condições locais, purificando o ar, mitigando a formação de "ilhas de calor" e protegendo a fauna; além de promover efeitos significativos no paisagismo, como o sombreamento, que é importante para a formação de espaços para o descanso e a contemplação. Entretanto, o planejamento e a gestão da arborização urbana envolvem um conjunto de atividades complexas, como a escolha, a implantação, a manutenção a remoção das espécies utilizadas, e principalmente em relação à destinação dos resíduos arbóreos.

Diante do cenário exposto, o artigo tem como objetivo analisar a qualidade dos espaços verdes do bairro Cafezal em Londrina - Paraná, através do cálculo de índice de área verde (IAV) e abordar a relação entre as questões legais vigentes e o quadro atual das áreas verdes e da arborização urbana presente.

\section{O CONCEITO DE INFRAESTRUTURA VERDE}

Há muito tempo vem se discutindo a respeito dos sistemas de áreas verdes no espaço urbano, entretanto, o conceito de infraestrutura verde começou a cerca de 150 anos com estudos sobre a paisagem e as inter-relações do homem com a natureza (Benedict e McMahon, 2009). As primeiras apoio institucional supported by
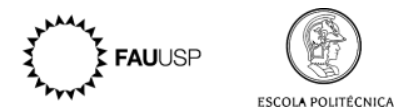
propostas de planejamento baseado na relação cidade-natureza tiveram o propósito de preservar o ambiente natural frente ao avanço das cidades. Um projeto importante foi o Emerald Necklace, em Boston, EUA, no final do século XIX, do arquiteto e paisagista Frederick Law Olmsted - primeiro projeto paisagístico de cunho ambiental e estruturador do desenvolvimento da cidade, cujo objetivo principal foi o controle das cheias e da melhoria da qualidade da água a fim de solucionar os problemas de enchentes e poluição das várzeas do rio Back Bay.

Em síntese, o conceito de infraestrutura verde abrange diversas definições, podendo referir-se desde o plantio de árvores que tragam benefícios ecológicos em áreas urbanas até estruturas de engenharia como manejo de enchentes ou tratamento de águas (Franco, 2010). No planejamento e desenho ambiental, a infraestrutura verde pode ser entendida como uma rede interconectada de áreas verdes naturais e outros espaços abertos que conservam valores e funções ecológicas e diversos benefícios para as pessoas.

\section{MÉTODO DE ANÁLISE}

Para o desenvolvimento do trabalho, foi calculado o índice de área verde (IAV), um dos instrumentos utilizados no planejamento urbano, para avaliar a qualidade de vida da população. O IAV expressa a relação entre a área dos espaços verdes, em $\mathrm{m}^{2}$, e a quantidade de habitantes da região analisada. A Sociedade Brasileira de Arborização Urbana sugere, no mínimo, $15 \mathrm{~m}^{2}$ de área verde por habitante (SBAU, 1996).

Para a classificação do IAV, considerou-se apenas a somatória das áreas dos espaços analisados, não sendo considerada a projeção das copas das árvores no cálculo de área, em relação ao número de habitante total do bairro. Os índices calculados considerados foram: índice de área verde para área de preservação da mata nativa; índice de área verde para praças; índice de área verde para fundos de vale; índice de área verde para áreas ajardinadas do sistema viário; e índice de área verde total. A equação (1) do IAV segue descrita abaixo:

$$
\mathrm{IAV}=\sum \mathrm{A} / \mathrm{Nh}
$$

onde IAV - Índice de área verde ( $\left.\mathrm{m}^{2} / \mathrm{hab}.\right)$;

A - Área $\left(\mathrm{m}^{2}\right)$;

Nh - Número de habitantes (hab.).

\section{RESULTADOS E DISCUSSÃO}

O Município de Londrina está situado na região norte do Estado do Paraná, com uma população de 569.733 habitantes (IBGE, 2019). A área de estudo corresponde ao bairro Cafezal localizado na zona sul de Londrina (Fig. 1). A região possui aproximadamente 2,57 $\mathrm{km}^{2}$ e 13.715 habitantes de acordo com os setores censitários (IBGE, 2010). O bairro Cafezal, que pertencia ao vazio urbano da periferia da cidade, desenvolveu-se a partir da ação de políticas públicas de habitação iniciada na década de 1980 e realizada pela Companhia de Habitação de Londrina (COHABLD).

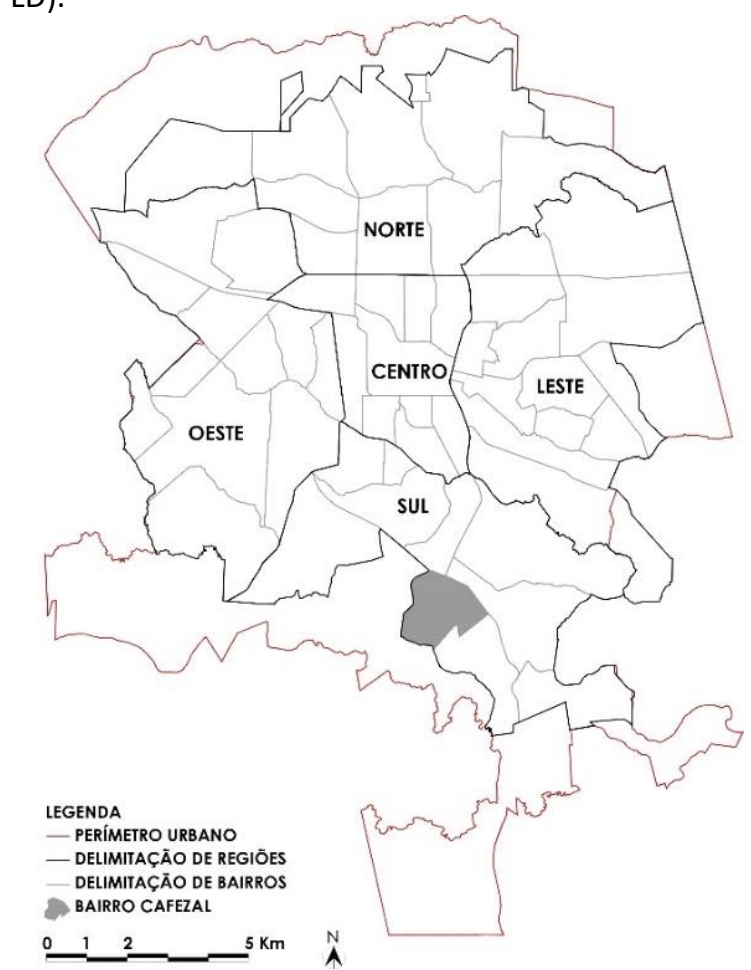

Figura 1: Mapa da cidade de Londrina e localização do bairro Cafezal. Fonte: Base de dados SIGLON (2019), alterada pela autora (2020)

Em relação a definição dos termos, a Lei $n^{\circ} 11.471$ (Londrina, 2012), que institui o código ambiental do município de Londrina, define no art. $4^{\circ}$ no inciso III áreas verdes como "espaços livres, de uso público, com tratamento paisagístico, reservadas a cumprir múltiplas funções de contemplação, repouso, preservação e lazer, nelas permitindo-se a instalação de mobiliário urbano de apoio a estas atividades, mediante aprovação da Secretaria Municipal do Ambiente (SEMA), respeitadas as áreas de preservação ambiental". A lei integra como sistema de áreas verdes as praças e os parques lineares, que deverão ser delimitadas por meio-fio e calçadas e providas de cobertura vegetal arbórea, por meio da preservação da vegetação original ou de replantio de espécies arbóreas nativas, conforme indicação da SEMA, além da arborização viária.

Diante do conceito de áreas verdes, a análise possibilitou coletar os dados representados abaixo (Tabela 1). 


\begin{tabular}{l|l|l|l} 
Índice & $\begin{array}{l}\text { Área } \\
\left(\mathbf{m}^{\mathbf{2}}\right)\end{array}$ & $\begin{array}{l}\mathbf{N}^{\circ} \text { de } \\
\text { Hab. }\end{array}$ & $\begin{array}{l}\mathbf{I A V} \\
\left(\mathbf{m}^{\mathbf{2}} / \mathbf{h a b} .\right)\end{array}$ \\
\hline $\begin{array}{l}\text { IAV para } \\
\begin{array}{l}\text { Preservação } \\
\text { da Mata } \\
\text { Nativa }\end{array}\end{array}$ & $12.036,97$ & 13.715 & 0,87 \\
\hline IAV Praças & $26.224,46$ & 13.715 & 1,91 \\
\hline $\begin{array}{l}\text { IAV Fundos } \\
\text { de Vale }\end{array}$ & $415.890,61$ & 13.715 & 30,32 \\
\hline $\begin{array}{l}\text { IAV Áreas } \\
\begin{array}{l}\text { Ajardinadas } \\
\text { do Sistema }\end{array}\end{array}$ & $23.327,28$ & 13.715 & 1,70 \\
$\begin{array}{l}\text { Viário } \\
\text { IAV Total }\end{array}$ & $477.389,31$ & 13.715 & 34,80
\end{tabular}

Tabela 1: Cálculo dos índices de áreas verdes do bairro Cafezal. Fonte: Autora (2020)

O bairro Cafezal apresenta uma área de preservação da mata nativa, quatorze praças, dois fundos de vale e áreas ajardinadas do sistema viário (Fig. 2), resultando em um IAV total de $34,80 \mathrm{~m}^{2} / \mathrm{hab}$., superior ao definido pela Sociedade Brasileira de Arborização Urbana (SBAU, 1996) de no mínimo 15 $\mathrm{m}^{2} / \mathrm{hab}$, entretanto será analisado cada espaço que compõe o sistema de áreas verdes.

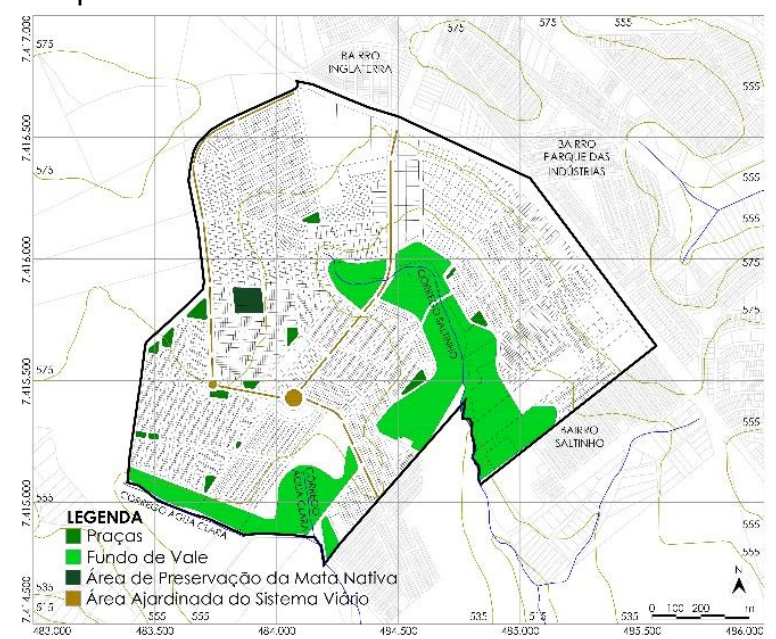

Figura 2: Mapa das áreas verdes do bairro Cafezal em Londrina-PR. Fonte: Base de dados SIGLON (2019), alterada pela autora (2020)

\subsection{A área de preservação da mata nativa}

A área de preservação da mata nativa tem um importante papel ambiental que se deve manter, como controle a ocupação urbana desordenada. É um espaço onde foram preservadas toda a vegetação nativa dentro do processo de urbanização do bairro.

\subsection{As praças}

A Lei $n^{\circ} 11.672$ (Londrina, 2012), que dispõe sobre o parcelamento do solo para fins urbanos no município de Londrina e dá outras providências, define praça como espaço destinado ao lazer e a recreação, no entanto, a maioria das praças da unidade territorial não apresentam mobiliário, equipamento e arborização que possibilitam essas atividades. A manutenção dos espaços livres nunca foram prioridades do Poder Público, observa-se pelo atual estado das praças e a Lei Orgânica do Município de Londrina (Londrina, 1990), contribui para isso, pois afirma que após 10 anos sem manutenção pode-se trocar o uso, assim, os outros setores de planejamento, vêem como uma oportunidade de apropriar-se dessas áreas, pois esses espaços são vistos como terrenos ociosos, terrenos vazios e sem função no espaço urbano. Dessa forma, como a arborização das praças não possui manutenção pela prefeitura, os próprios moradores acabam se apropriando das praças formando seus próprios espaços de lazer como bancos e mesas a partir de troncos de árvores (Fig.3).

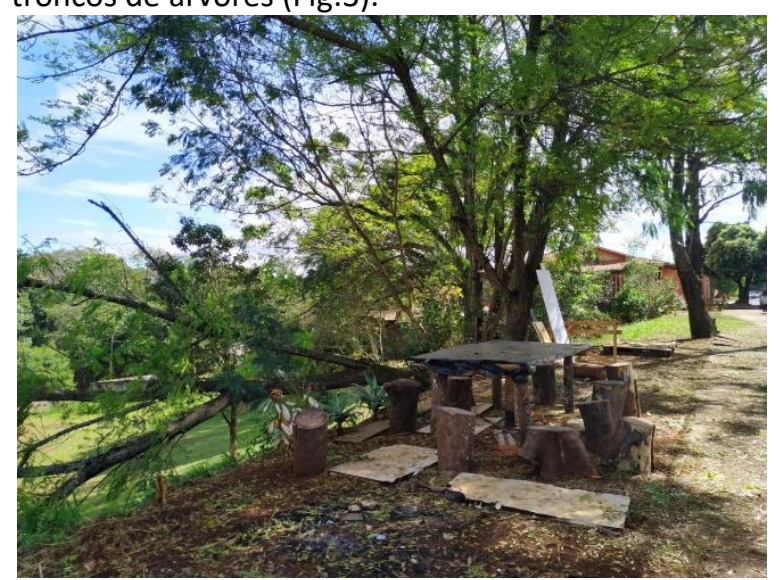

Figura 3: Praça do bairro Cafezal em Londrina-PR. Fonte: Autora (2020)

\subsection{Os fundos de vales}

A Lei $n^{\circ}$ 12.651/2012 (Brasil, 2012), que dispõe sobre a proteção da vegetação nativa, das áreas de preservação permanente (APP) e das áreas de reserva legal, no inciso II do art. $3^{\circ}$ define APP como "área protegida, coberta ou não por vegetação nativa, com a função ambiental de preservar os recursos hídricos, a paisagem, a estabilidade geológica e a biodiversidade, facilitar o fluxo gênico de fauna e flora, proteger o solo e assegurar o bem-estar das populações humanas". Ainda de acordo com a Lei, a APP é delimitada em largura mínima de 30 metros em zonas urbanas; a vegetação situada deverá ser mantida; a intervenção ou a supressão de vegetação nativa somente ocorrerá nas hipóteses de utilidade pública, de interesse social ou de baixo impacto ambiental; e no caso de eliminação é obrigado a promover a recomposição da vegetação em que deverão ser priorizados projetos que contemplem a utilização de espécies nativas do mesmo bioma onde ocorreu a supressão a fim de assegurar a conservação das espécies. Já na área do entorno da nascente é necessário um raio mínimo de proteção de 50 metros.

Em Londrina, além da APP, a Lei $n^{\circ} 11.471$ (Londrina, 2012), define no art. $4^{\circ}$ no inciso XLIV outra 
área de proteção, a faixa sanitária, como "área não edificável contígua às áreas de preservação permanente, com objetivo de constituir zona de amortecimento entre as matas ciliares e as vias de circulação, além de servirem de passagem para elementos de sistema de saneamento ou demais equipamentos de serviços públicos". De acordo com a Lei $n^{\circ} 11.996$ (Londrina, 2013), que institui o plano diretor de arborização do município de Londrina, a faixa sanitária deve ter largura de $\mathbf{3 0}$ metros a partir da APP do fundo de vale.

O bairro Cafezal apresenta em seu território áreas de fundo de vale, que conforme a Lei $n^{\circ} 11.471$ (Londrina, 2012), são constituídos pelos cursos hídricos, APP, faixa sanitária e áreas verde, até a via mais próxima projetada ou executada, em que suas áreas são inedificáveis, e devem atender a implantação de parques lineares destinados às atividades de recreação e lazer, à proteção das matas nativas, à drenagem e à conservação de áreas críticas. Observa-se que nos fundos de vale não há implantação dos parques lineares como deveria ocorrer, apenas algumas áreas gramadas com possibilidades para praticar o futebol, apresentam vários tipos de extratos arbóreos, porém há concentração de árvores de alto porte, não apresentam calçadas e encontram-se, de acordo com Lei $n^{\circ} 12.236$ (Londrina, 2015), que dispõe sobre o uso e a ocupação do solo no município de Londrina e dá outras providências, na zona especial de fundo de vale e preservação ambiental, ZE-4. Identifica-se ocupações irregulares nas APP dos fundos de vale que configuram um quadro de pobreza urbana e precariedade quanto ao acesso a moradia. Alguns trechos da faixa sanitária encontram-se urbanizadas, no entanto, esse processo é legal, visto que os loteamentos foram aprovados anterior a Lei $n^{\circ} 11.471$ (Londrina, 2012). Além disso, as nascentes dos córregos não apresentam um raio de proteção de 50 metros, pois encontra-se na área um loteamento com edificações. A ocupação nessa área e as ocupações irregulares no fundo de vale podem contribuir para a ocorrência de deslizamentos, em função da declividade e da impermeabilização do solo.

Outro fator importante em relação aos fundos de vale refere-se ao depósito irregular de lixo em diversos trechos que juntos com os resíduos arbóreos geram impactos negativos para a flora, a fauna e inclusive para a própria população, pois as águas da chuva carregam os sedimentos para dento dos córregos, causando a poluição hídrica com a contaminação da água e a proliferação de doenças (Fig. 4).

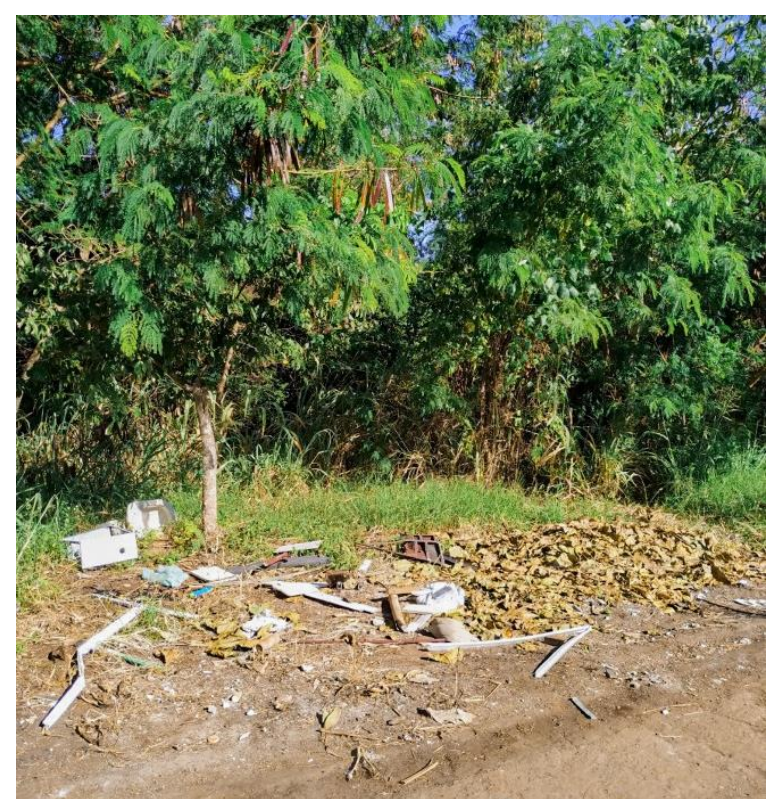

Figura 4: Locais irregulares de descartes de resíduos no fundo de vale do bairro Cafezal em Londrina-PR. Fonte: Autora (2020)

\subsection{As áreas ajardinadas do sistema viário}

De acordo com a Lei no 12.587 (Brasil, 2012), que institui as diretrizes da política nacional de mobilidade urbana e dá outras providências, é objetivo do planejamento urbano a integração entre diferentes modos de transporte, como coletivo, individual e não motorizado, a fim de melhorar as condições de acessibilidade e de mobilidade das pessoas e cargas no território. A falta do incentivo à caminhada e ao uso da bicicleta como transporte alternativo na unidade territorial alavanca a forte dependência do automóvel individual, visto que as ruas não são convidativas e atrativas a comunidade, principalmente pela falta da arborização viária, pela carência de diversidade de tipologias de espécies e pela falta de sombreamento nos passeios públicos.

O Instituto de Planejamento Urbano de Londrina (IPPUL) possui o projeto "calçada para todos" cujo objetivo é a melhoria da acessibilidade nas calçadas da cidade de Londrina, oferecendo condições seguras e confortáveis aos pedestres, visando atender os diferentes usuários e, principalmente, aquelas pessoas com dificuldade de mobilidade, como pessoas com bengalas, muletas, andadores ou cadeirantes. 0 projeto segue as dimensões mínimas de circulação e deslocamento nas calçadas previstas na Norma Brasileira de acessibilidade a edificações, mobiliário, espaços e equipamentos urbanos (NBR 9050). Além disso, deve apresentar uma faixa gramada de $70 \mathrm{~cm}$ a partir do meio fio para implantação da arborização em que a escolha do tipo de árvore e a forma de plantio garante o crescimento adequado das raízes, evite que danifique o piso das calçadas e proporciona maior sombreamento, proteção e conforto aos pedestres, além de embelezar o espaço urbano. A Lei $n^{\circ} 8563$ 
(Londrina, 2001), que dispõe sobre a substituição das espécies de arborização pública que menciona e dá outras providências, define que as árvores que tenham problemas de sanidade ou causem danos as calçadas das vias, das praças e dos logradouros públicos devem ser trocadas por espécies adequadas, sob supervisão e orientação da SEMA, e aquelas plantadas em desacordo com o Plano de Urbanização do Município serão substituídas gradativamente pela SEMA. A Lei menciona que "a madeira das espécies vegetais substituídas, após a necessária industrialização, será estocada e usada na construção de habitações populares a cargo da Companhia de Habitação de Londrina (COHAB/LD) ou distribuída gratuitamente aos ocupantes de favelas ou assentamentos". No entanto, as calçadas do bairro apresentam barreiras e saliências no seu trajeto, que prejudicam o deslocamento a pé das pessoas, pois não estão padronizadas de acordo com o projeto e o carece de arborização adequada, principalmente pela falta da efetivação dos planos mencionados (Fig. 5).

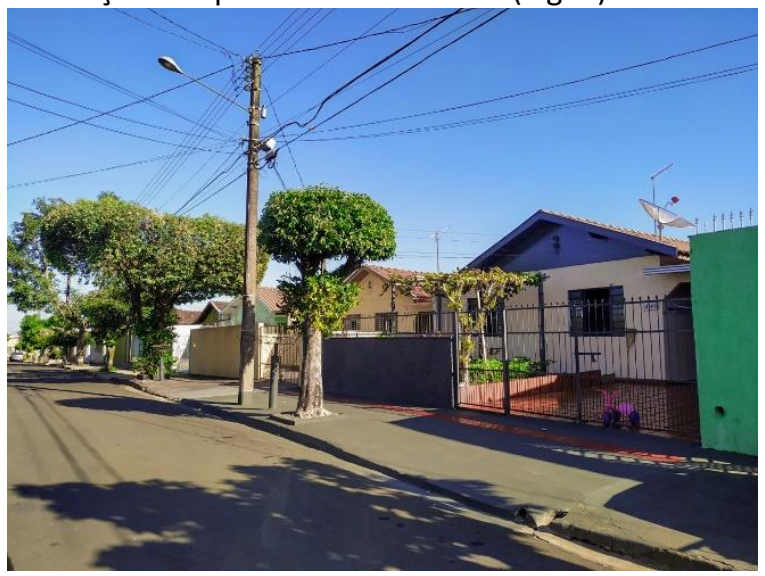

Figura 5: Conflito entre a arborização e a fiação da rede elétrica no bairro Cafezal em Londrina-PR. Fonte: Autora (2020)

\subsection{O memorial botânico}

O memorial botânico representa a riqueza da biodiversidade de espécies vegetais, principalmente autóctone, com variedade de nichos e habitats ecológicos que compõe o ecossistema urbano a fim de contemplar o potencial que os espaços livres de uso público oferecem nos serviços ecossistêmicos da unidade territorial. A arborização tem importância crucial no sistema biológico urbano, a sua presença nas ruas, praças, áreas verdes e parques são insubstituíveis ao contribuir para a qualidade do ar e da água, reduzir o consumo de energia, capturar gases do efeito estufa e prevenir processos de erosão, sedimentação e alagamentos.

Em Londrina, a arborização deve seguir os parâmetros que garantem a preservação da genética local e a biodiversidade de espécies estabelecidos no art. 24 da Lei no 11.996 (Londrina, 2013). Quanto à origem, serão, no mínimo, $70 \%$ nativas, sendo $30 \%$ autóctones e $40 \%$ nativas brasileiras e, no máximo, $30 \%$ exóticas não invasoras. Quanto à diversidade, serão, no máximo, $10 \%$ da mesma espécie, $20 \%$ do mesmo gênero e $30 \%$ da mesma família botânica. Quanto aos passeios das vias de fundo de vale, a arborização segue o art. 27, em que serão adotadas, no mínimo, $40 \%$ autóctones e, no máximo, $60 \%$ de espécies nativas brasileiras. Em contrapartida, o bairro carece de diversidade em relação à arborização.

\subsection{Os elementos cênicos}

Os elementos cênicos identificam as características intrínsecas dos elementos físicos que compõem os espaços e são percebidos através da análise visual (Tardin, 2016). O bairro possui fundos cênicos, que são vistas mais amplas da paisagem, percebidas pela cota mais elevada, devido a declividade, expressando a singularidade do relevo junto com a massa verde, densa e extensa que ocupa a maior parte do fundo de vale, representando o contraste e suas particularidades entre o ambiental natural e o espaço edificado (Fig. 6).

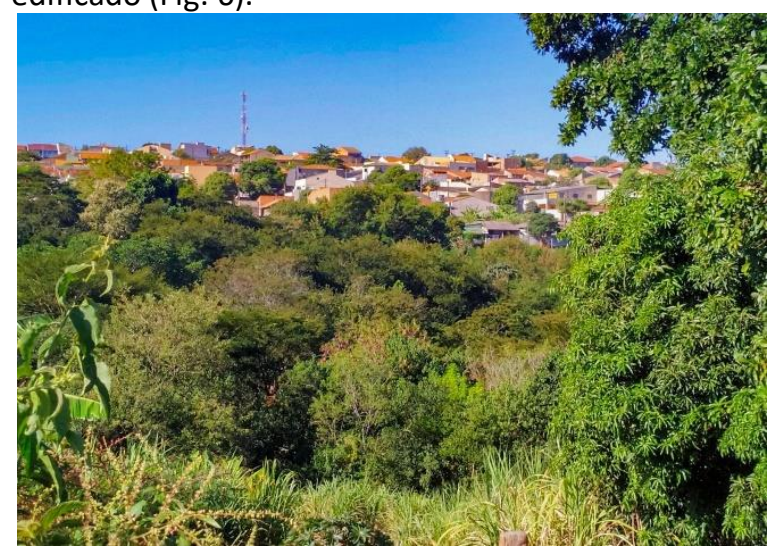

Figura 6: Fundo cênico retrata a paisagem da unidade territorial. Fonte: Autora (2020)

\subsection{Os resíduos da arborização urbana}

Os resíduos da arborização urbana de Londrina são descartados no Viveiro Municipal de Londrina, na antiga fazenda Refúgio, a qual é utilizada como material de adubo para as hortas das escolas municipais. Além disso, há uma fábrica que manejam os resíduos como matéria-prima para a formação e venda de briquetes.

\section{CONCLUSÃO}

O processo de urbanização faz com que a população desconheça os benefícios dos espaços verdes e da arborização. A solução com projetos de infraestrutura verde, viabilizariam além de ganhos ecológicos, como o aumento da permeabilidade do solo e melhora na qualidade do ar, ganhos significativos na qualidade de vida da população. 0 estudo pontuou as deficiências das áreas verdes do bairro Cafezal, principalmente pela falta de uma arborização adequada, tanto nos passeios, quanto nas 
praças e nos fundos de vales, apesar das leis federais e municipais abordarem toda a questão ambiental e o bairro apresentar extensa área verde dentro do seu perímetro, o que garante um elevado índice de área verde. Outro fator importante, refere-se ao manejo dos resíduos arbóreos a qual falta incentivo em relação a novos usos, com foco na sustentabilidade, acabam não explorando o melhor potencial da madeira como matéria-prima.

\section{REFERÊNCIAS}

1. Benedict, M. A., McMahon E. T. (2009). Green infrastructure: linking landscapes and communities. Washington, DC: Island Press.

2. Brasil. Lei $n^{\circ} 12.587$, de 3 de janeiro de 2012 . Institui as diretrizes da política nacional de mobilidade urbana; revoga dispositivos dos Decretos-Leis $\mathrm{n}^{\circ} \mathrm{s}$ 3.326, de 3 de junho de 1941, e 5.405, de 13 de abril de 1943, da Consolidação das Leis do Trabalho (CLT), aprovada pelo Decreto-Lei $n^{\circ} 5.452$, de 10 de maio de 1943, e das Leis $n^{\circ}$ s 5.917, de 10 de setembro de 1973, e 6.261, de 14 de novembro de 1975; e dá outras providências. Diário Oficial da República Federativa do Brasil, Brasília, DF, 4 de janeiro de 2012.

3. Brasil. Lei $n^{\circ} 12.651$, de 25 de maio de 2012. Dispõe sobre a proteção da vegetação nativa; altera as Leis $\mathrm{n}^{\circ}$ 6.938, de 31 de agosto de 1981, 9.393, de 19 de dezembro de 1996, e 11.428, de 22 de dezembro de 2006; revoga as Leis $n^{\circ} 4.771$, de 15 de setembro de 1965, e 7.754, de 14 de abril de 1989, e a Medida Provisória no 2.166-67, de 24 de agosto de 2001; e dá outras providências. Diário Oficial da República Federativa do Brasil, Brasília, DF, 25 de maio de 2012. 4. Franco, M. A. R. (2010). Infraestrutura verde em São Paulo: o caso do corredor verde Ibirapuera-Villa Lobos. Revista LABVERDE, São Paulo, v. 1, set, 135-154.

5. Londrina. Lei Orgânica, de 05 de abril de 1990. Lei orgânica do município de Londrina/PR. Publicada no Jornal Folha de Londrina, edição $n^{\circ}$ 11465, de 06 de abril de 1990, caderno encarte.

6. Londrina. Lei $n^{\circ} 8563$, de 05 de outubro de 2001. Dispõe sobre a substituição das espécies de arborização pública que menciona e dá outras providências. Publicada no Jornal Oficial, edição $n^{\circ}$ 336, de 14 de novembro de 2001.

6. Londrina. Lei $n^{\circ} 11.471$, de 05 de janeiro de 2012. Institui o código ambiental do município de Londrina. Publicada no Jornal Oficial, edição $n^{\circ}$ 1766, de 10 de janeiro de 2012.

7. Londrina. Lei $n^{\circ} 11.672$, de 24 de julho de 2012. Dispõe sobre o parcelamento do solo para fins urbanos no município de Londrina e dá outras providências. Publicada no Jornal Oficial, edição $n^{\circ}$ 1968, de 10 de setembro de 2012, caderno único, fls. 21 a 25.

8. Londrina. Lei $n^{\circ} 11.996$, de 30 de dezembro de 2013. Institui o plano diretor de arborização do município de
Londrina. Publicada no Jornal Oficial, edição n² 2334, de 30 de dezembro de 2013.

9. Londrina. Lei $n^{\circ} 12.236$, de 29 de janeiro de 2015 . Dispõe sobre o uso e a ocupação do solo no município de Londrina e dá outras providências. Publicada no Jornal Oficial, edição $n^{\circ} 2637$, de 02 de fevereiro de 2015.

10. SBAU (1996). Carta a Londrina e Ibiporã. Boletim Informativo. v.3, n.5, 3.

11. Tardin, R. (2016). Espaços livres: sistema e projeto territorial. 2. ed. Rio de Janeiro: Rio Book's.

12. Vasconcellos, A. A. (2015). Infraestrutura verde aplicada ao planejamento da ocupação urbana. Curitiba: Appris. 